\title{
Incumbents' Interest, Voters' Bias and Gender Quotas
}

G.R. Fréchette and François Maniquet

Discussion Paper 2006-42

\section{Département des Sciences Économiques de l'Université catholique de Louvain}




\title{
Incumbents' Interests, Voters' Bias and Gender Quotas*
}

\author{
Guillaume R. Fréchette \\ FranCoIS MANIQUET \\ New York University \\ C.O.R.E. \\ Massimo MorelLi \\ The Ohio State University
}

March 2006

CORE Discussion Paper 2006/83

\begin{abstract}
The adoption of gender quotas in party lists has been a voluntary decision by many parties in many countries, and is now a subject of discussion in many others. The Parity Law passed in France in 2001 is particularly interesting because for the first time the quota was set at 50 percent, and the deputies passing the reform are elected in single member districts. In this paper we rationalize parity on the basis of the self interest of male incumbent deputies: The existence of a voters' bias in favor of male candidates is sufficient to convince the
\end{abstract}

\footnotetext{
${ }^{*}$ We are highly indebted to Joan Scott for inspiring us and for many crucial discussions on the parity movement in France. We are grateful to the Institute for Advanced Study in Princeton for providing an excellent research environment when Maniquet and Morelli began this project. Comments by Matt Jackson, Dean Lacy, Matthias Messner, Kira Sanbonmatsu, Gilles Serra, Guido Tabellini, Jack Wright and by the participants at various workshops are gratefully acknowledged. We thank Ji Li for her assistance with the data and John Lightle for proofreading the paper. Morelli gratefully acknowledges the financial support of the National Science Foundation (Grant SES0213312) and the Deutsche Bank. Maniquet thanks the Belgian Program on Interuniversity Poles of Attraction initiated by the Belgian State, Prime Minister's Office, Science Policy Programming. Fréchette's research was partially supported by the Center for Experimental Social Science, the C.V. Starr Center and the National Science Foundation (Grant SES-0519045). Any opinions, findings, and conclusions or recommendations in this material are those of the authors and do not necessarily reflect the views of the institutions supporting the project.

Corresponding author: Massimo Morelli, morelli.10@osu.edu.
} 
incumbents to advocate for equal gender representation in party lists, because it raises the incumbents' chances of being re-elected. We confirm empirically the existence of male bias in the French electorate and we show that parity law may have Assembly composition effects and policy effects that vary with the electoral system. 


\section{Introduction}

In 2001 the French Parliament passed a law - the so called "parity law" - that forces parties to choose roughly equal numbers of men and women as candidates in their lists. What can motivate the members of a male dominated Parliament to make this strong kind of gender representation reform? Can the choice of a parity law be consistent with the self interest of the incumbent (men) politicians who passed the law? Why were deputies almost unanimously in favor of the reform while the senators were mostly opposed? Why did the reform take the form it took? Why was it so little effective at the national level, especially when compared with the more successful reforms in Argentina, Belgium and Costa Rica? This paper aims to provide a consistent set of answers to all these questions, by means of a simple formal model of constitutional reform incentives as well as empirical analysis. We view this also as an important first step towards understanding more generally the conditions under which the self interest of a majority can suffice to explain the introduction of laws that prima facie protect or foster minority interests.

The adoption of gender quotas in party lists has been a voluntary decision by many parties in many countries, and is now a subject of discussion in many others. ${ }^{1}$ The parity law that passed in France in 2001 stands out from all other cases, because it was forced by the members of parliament on all parties simultaneously without much prior voluntary decision by individual parties, it establishes the highest quota (50 percent) among the existing ones, and it is the only case of strong gender quotas for chambers using single member district elections. Finally, it is also noteworthy that in spite of its strong form, the effectiveness of the law has been very limited,

\footnotetext{
${ }^{1}$ For a cross national empirical study of the voluntary adoption of gender quotas in the last 30 years see for example Caul [2]. For a well documented contagion theory of such a process of voluntary adoption see for example Matland and Studlar [11], who also provide convincing preliminary evidence that such a contagion leading to the diffusion of gender quotas across parties is more likely to happen in countries that use proportional representation electoral systems. Since we are studying instead the constitutional incentives of the members of Parliament when discussing a law that would apply to all parties simultaneously, this literature on voluntary adoption and contagion is complementary but not directly related to our question and motivation. Another related phenomenon that we won't discuss in this paper is the adoption of legal quotas directly in terms of seats. For the latter type of experiences see e.g. Duflo and Chattopadhyay [7].
} 
even lower than for countries that established a lower quota. ${ }^{2}$

Moreover, France offers us a quasi-natural experiment opportunity to illustrate the role of electoral systems in the application and effectiveness of gender quota legislations, given that the two national chambers and the city councils have three radically different electoral systems. We shall provide a number of insights on the role of electoral systems in terms of the ex-ante incentives to pass the law as well as in terms of the ex-post differences in gender representation effects and policy effects. The ex-ante reasoning of incumbent legislators that we uncover can also be extended to a broader set of contexts, and could help to explain the emergence of many types of affirmative action laws. The ex-post effects that we discuss clarify some important externalities between electoral reforms and gender representation reforms.

The French Assembly is formed using single-member-district majority rule. The Senate is elected using plurality rule in small districts and proportional representation in large ones. Finally, municipal elections employ a two-round proportional representation system with a fifty percent majority bonus for the plurality winner of the second round. The two chambers, the Assembly of deputies and the Senate, are called by the Constitution to vote together on constitutional reforms like the one discussed here. Since the Assembly is much larger than the Senate, the almost unanimous support of the reform in the Assembly is the main fact to be explained, being almost necessary and sufficient for the approval of the reform. The parity reform takes different forms in the different types of elections, and in the case of the Assembly it means that each party should have between $48 \%$ and $52 \%$ of candidates of each gender across districts. The other two types of elections use "closed party lists" (except the senatorial elections in small districts where it is a two-round plurality rule but parity does not apply), and the parity reform requires the parties to alternate men and women in the lists.

The common explanation of the approval of the parity law, in newspapers and among parity observers, is that parity law was passed because parties realized that "the French people wanted it." 3 The first thing we do in this paper is to show that

\footnotetext{
${ }^{2} \mathrm{~A}$ summary of the legislations and effects of gender quotas across countries and electoral systems can be found in table 1 of Jones [9].

${ }^{3}$ This is the view developed, for instance, by the official "Observatoire de la parité entre les
} 
the above claim does not find empirical support. In contrast, in the relevant period we find evidence of "male bias" in the electorate. Controlling for observables, when a new (or incumbent) male candidate runs against a woman, he does better than male and female new (or incumbent) candidates running against an opponent of the same sex. Similarly, females running against males do worse than females running against females. The advantage that male candidates enjoy over female candidates in the data could in principle be a consequence of (1) voters' preferences (not necessarily on gender per se, but rather on any other unobservable characteristic correlated with gender), or (2) from an explicit bias of party leaders when they decide list compositions and placement of candidates in the various districts. ${ }^{4}$ We show that the male advantage is not the result of party bias, since new male candidates are not placed in districts more favorable to their party than new female candidates. In other words, the empirical analysis establishes that the most relevant form of bias against female candidates is among voters, and is not an artifact of a strategic male conspiracy by party leaders. The gender of the new candidates is not correlated to the party's performance in their district at the previous election. ${ }^{5}$

These empirical findings suggest that the reason why parity law was approved without opposition by the members of Parliament elected in single member districts may be the opposite of the common explanation, which is based on a claim of electorate demand. If the MPs could anticipate that women challengers have, on average, a weaker electoral support, consistent with the male bias in the electorate that the data display, then they could expect weaker challengers on average by passing parity. Even if the MPs believed that in the long or medium run the electorate will have no male bias, it is quite likely, in our opinion, that most politi-

femmes et les hommes" in their report to the Prime Minister following the elections (see Zimmerman $[17])$.

${ }^{4}$ We will call this second hypothesis "party bias", and is obviously related to the "male conspiracy theory" proposed in Duverger [8].

${ }^{5}$ In closed party list systems it is obviously impossible to directly test the existence of a male bias among voters, since voters vote for parties, not candidates. Hence the only systems in which voters' bias can be empirically tested against party hierarchy's bias are plurality systems or open list systems. In the Anglo-Saxon pluralitarian systems a number of studies suggest that there is no voters' hostility against female candidates (see e.g. Darcy et al. [5], Welch et al. [16], Darcy and Schramm [4] and Burrell [1] for the US), whereas there is some evidence of party bias (see e.g. Sanbonmatsu [14]). This is clearly the opposite of our findings for France. 
cians anticipated at least a short run male advantage, due to the experience and recognition advantages of party insiders. Our data do not support the hypothesis that male advantage is due to experience alone, but even if it were, the logic of our findings would be unchanged: If for whatever reason the MPs expected some average male advantage, then parity law must have been perceived as not dangerous for the current incumbents, and this explains the approval of the law.

A peculiar feature of the French Parity Law, as approved in 2001, is that if a party does not satisfy the law it must pay per violation fees (or suffer proportional reductions in government funding). The main right wing party (UMP) presented in 2002 only $19.93 \%$ of women and paid EUR 4M, representing $15.8 \%$ of its government funding, while the main left wing party (a coalition led by the Socialist Party) presented $36.13 \%$ of women and lost $9.1 \%$ of its funding (see Jourdain [10]). ${ }^{6}$ The common explanation for the possibility to violate the law by paying fees relates to the pressure of male incumbents within the parties to remain candidates in favorable districts. As mentioned above, this informal explanation does not find support in the French data, and would be inconsistent with the unanimous support given to the law. The only intuitive justification (among those commonly put forward) that could in principle reconcile the passage of the law with the permission to violate it by paying fees, is what we could call the "symbolic gesture" hypothesis. One problem with this informal explanation is that a symbolic gesture is politically relevant for every party only if the equality of gender representation reflects voters' preferences, which is one thing our data allow us to doubt. In any case, even if one grants some intuitive value to the symbolic gesture hypothesis, there is also an alternative explanation, which is perfectly consistent with the self interest of incumbents at the constitutional design table, and consistent with all the other explanations we propose in the paper. Our formal model suggests that passing parity with the provision of possible fees dominates all other options (namely the status quo and pure parity without violations allowed) if the re-election of incumbents matters more to party leaders than the election of new candidates. The argument goes as follows: Given the voters' bias in favor of men candidates, parties are in favor of a gender quota because it increases the incumbents' probability (conditional on

\footnotetext{
${ }^{6}$ Note that in France campaign financing is very restricted, so that these reductions in party funds have non trivial consequences.
} 
running) of running against a woman and be re-elected. On the other hand, pure parity (with no violations allowed) decreases the probability for the male incumbents of a large party to run again. Therefore, fees are rationalizable as they constitute a direct way to make more incumbents run than the strict application of parity would allow. The ex-ante drawback of parity with fees is that if one party pays fees, this obviously decreases the other party's incumbents' chances of running against a woman. Therefore it is not always true that parity with fees ex-ante dominates both strict parity and no-parity. One sufficient condition for this to be true is the existence of a (realistic) preference by party leaders for incumbents over new candidates. Given this party preference for re-electing incumbents over electing new candidates, if fees are sufficiently large, parties are willing to pay them only in order to allow incumbents to run. Parity with fees, then, has the two attractive properties (for the incumbents) that (1) it increases the probability for incumbents to run against women, and (2) it does not prevent incumbents from large parties to run.

The intuition for the opposition of the senators is more straightforward than the above intuition for the support given to the reform by the deputies, and it is a direct consequence of the electoral formula. To see this, assume for simplicity (and almost realistically) that all the incumbent senators are men. Senatorial elections are conducted using Closed List Proportional Representation (CPR henceforth), and parity law requires each party to alternate men and women in the candidate list. Given that voters can only choose among parties and the $k$ seats assigned to a party go to the top $k$ candidates in the party list, parity law determines an automatic substitution of incumbents with female candidates. ${ }^{7}$ In summary, single member district (henceforth SMD) majority rule, given the presence of some degree of male bias, allows the incumbent deputies to gain from the parity law; whereas the opposite is true for the senators given CPR.

In terms of ex-post effects, the first question concerns the gender representation outcome: The 2002 Assembly elections resulted in only a moderate increase in the percentage of women elected, from $10.9 \%$ to $12.3 \%$, and the result was not much

\footnotetext{
${ }^{7}$ In contrast, in an Open List system like the Belgian one, the assignment of seats within a party depends on the relative number of votes received by the candidates, and with this system PR would not automatically imply a one-to-one mapping between parity in the list and parity in the outcome.
} 
better than this in the 2001 and 2004 Senate elections. The reason for the low effectiveness in Assembly elections is related to the presence of male bias among voters and, potentially, to incumbency advantage of other sources. Given the evidence provided in this paper about male bias in the French voters' population, passing the Parity Law only helped strengthen ex-post the incumbency advantage of the already elected deputies. This, in conjunction with the extensive use of fees, explains the low effectiveness. On the other hand, the low effectiveness in Senate elections is due to "party proliferation" strategies: incumbent senators managed to keep their seats by becoming leaders of new lists. ${ }^{8}$

As a side ex-post phenomenon, it is also interesting to note that parity law can affect the party composition of the Assembly. In particular, parity law should be expected to favor the party with the largest number of incumbents when policy preferences alone would make it lose many seats. The intuition for this result is simply that, as parity helps incumbents, some of them are re-elected in spite of a sharp decrease in the voters' preference towards the platform they defend. Under CPR the party composition effects may be more difficult to predict, because of integer problems related to the D'Hondt formula and because of the heterogeneity of incumbency advantage across list members.

The low effectiveness of the parity law for the two national elective bodies contrasts with its performance at the municipal level, where women obtained 47.5 percent of the seats. In section 4 we will explain, among other things, why with an electoral system and a gender quota rule like those used in the French municipal elections male bias could not play a role nor was it possible to make use of the same party proliferation strategies used in the Senate elections. More generally, our analysis confirms that gender quota legislation is more likely to be effective in proportional representation systems with large districts and the addition of a minimum threshold (in order to discourage party proliferation), although some open questions remain on the difference between closed list and open list, given the uncertainty about voters' versus party bias in the various countries using proportional representation. Moreover, our analysis will clarify that electoral reforms that make

\footnotetext{
${ }^{8}$ Some evidence of a link between gender quota legislation and number of lists can also be obtained by comparing the number of municipal lists of minor parties in Costa Rica from 1994 to 2002, as documented in Jones [9] (table 2).
} 
parity laws more likely to be effective are, on the other hand, likely to generate opposition by the incumbents. In other words, the message here is that if such an electoral reform is made in a country before parity laws are discussed, it may make it harder to pass the parity law. As more countries will start debating reforms like the parity law, the empirical links between electoral systems and gender representation laws will become more transparent in the future. At the theoretical level, the externalities across different dimensions of constitutional reforms are definitely an understudied and important problem, of which we are providing a clear example.

The paper is organized as follows. We will first document our finding of male bias and no party bias in France. Based on the male bias found in the data, we will build the theoretical explanation of the constitutional decisions of the MPs about the parity reform. We will then highlight the relevant features of the senatorial races and we will elaborate on the electoral design issues mentioned above. We will conclude with some comparative remarks and some hints about the potentially important link between demand biases and affirmative action laws in general.

\section{Voters' Bias for the Assembly}

In this section we aim to show that in the 2002 French National Assembly election a male bias existed among voters. We define as male bias the additional percentage of votes a male candidate obtains, ceteris paribus, when he runs against a woman. We remark that by male bias we do not refer necessarily to discriminating preferences, but to whatever reasons may make voters have a net preference for men when all the other observable variables are kept constant. ${ }^{9}$

We need to show that the male advantage just displayed cannot be derived from party bias. As a party bias would result in a strategic allocation of men in favorable districts, we show below that the data does not exhibit such a party bias. In other words, no party has shown a biased preference for men over women in "good" districts where it did not have an incumbent.

Our data is based on information collected from the website of the French Na-

\footnotetext{
${ }^{9}$ For example, a male bias can arise from a wide-spread belief that men are more corrupt, or bring more pork to the district, whereas women are more concerned about global public goods, and the electorate of a district may prefer a focus on the former type of policies.
} 


\begin{tabular}{l|c|c|c|c|r} 
& M vs M & F vs F & M vs F & F vs M & Total \\
\hline New vs New & 16 & 12 & 17 & 17 & 62 \\
\hline New vs 97 Loser & 30 & 4 & 2 & 2 & 38 \\
\hline New vs Mover & 16 & 0 & 5 & 5 & 26 \\
\hline New vs Incumbent & 198 & 22 & 75 & 75 & 370 \\
\hline 97 Loser vs Mover & 8 & 4 & 1 & 1 & 14 \\
\hline 97 Loser vs Incumbent & 67 & 2 & 14 & 20 & 103 \\
\hline Mover vs Mover & 2 & 0 & 0 & 0 & 2 \\
\hline Mover vs Incumbent & 2 & 0 & 1 & 1 & 4 \\
\hline Total & 339 & 44 & 115 & 121 & 619
\end{tabular}

Table 1: Types of run-offs

tional Assembly. ${ }^{10}$ The website provides, among other things, biographical information on candidates from 2002 elections, their party affiliation and incumbency status, and the district-by-district first- and second-round results in both the 1997 and 2002 elections, together with abstention rate of each district. We have complemented this with data on candidate campaign expenditures and party contributions to each candidate's campaign from Publication Simplifiée des Comptes de Campagnes. ${ }^{11}$

In order to avoid difficulties associated with variable number of parties and the resulting strategic voting behavior, we focus on those districts where election went to the second-round and where the two second-round candidates were from the two main party coalitions of the 2002 elections, PS and UMP. ${ }^{12}$ Table 1 gives some descriptive statistics in terms of the frequency of the various "types" of run-offs. ${ }^{13}$

For observation/candidate $j$, we assume a linear model of the form $y_{j}=\beta X_{j}+\varepsilon_{j}$. Different specifications will be estimated, but in the basic one $y_{j}$ is candidate $j$ 's percentage of votes (henceforth score) in the second round of the 2002 elections.

\footnotetext{
${ }^{10} \mathrm{http}: / /$ www.assemblee-nationale.fr/elections

${ }^{11}$ Or, Simplified Publication of Campaign Accounts, which is published in the Official Journal of the French Rebublic in the Administrative Documents series.

${ }^{12}$ Only 10 percent of the districts assigned a seat in the first round.

${ }^{13}$ The letters $\mathrm{M}$ and $\mathrm{F}$ refer to the gender of the candidates; the term 97 loser clearly indicates a candidate who had been a candidate before but was not an incumbent; the term mover refers to a candidate who was elected in 1997 but in another district.
} 
Besides a variable measuring the male advantage, which we describe next, the vector $X_{j}$ of controls includes the score in the second-round of the 1997 election obtained by the candidate of the same district and same party as candidate $j .{ }^{14}$ This partydistrict-specific variable accounts for the aggregate preference toward a specific party within each district. A second control is age difference between opponents in the same district, since a candidate's age is plausibly correlated with his(her) perceived quality or experience (we deal with other indirect tests of the role of experience below). We also control for the difference of the square of their age. ${ }^{15}$ Finally, we control for party affiliations, since they could be correlated to the gender bias. This is done by including an indicator variable that takes value 1 if the candidate is from UMP and 0 if he or she is from PS. A constant term is also included, which represents the average score a candidate won in 2002 when all other regressors were zero. ${ }^{16}$ Error terms $\left(\varepsilon_{j}\right)$ follow standard assumptions imposed by the ordinary least squares estimation method. ${ }^{17}$

The key regressor is the male advantage. It can be measured by a variable that takes value 1 if a male has a female opponent, 0 if the two candidates are of the same gender, and -1 if a female has a male opponent. We will also show,

\footnotetext{
${ }^{14}$ Thus we also eliminate some observations that have no such correspondence in 1997, e.g. when no PS, RPR or UDF candidates ran in that district in 1997 or if they were eliminated in the first round. (Since the UMP did not exist in 1997 we use the score from the RPR or UDF.)

${ }^{15}$ Both are divided by 100 to make results easier to present.

${ }^{16} \mathrm{We}$ also considered controlling for the difference in expenditures between the candidates in the same district and the square of the difference. Out of the eight specifications reported in Tables 2 and 3 , these variables were statistically significant in only two cases. The biggest coefficient estimate (in absolute value) has its first non-zero digit in the fifth position past the decimal. More importantly, adding these regressors had no qualitative impact on the other estimates. The only difference worth noting is that three coefficient estimates lose statistical significance, "Age Difference" in specifications 1 and 2, and the "Difference of Square of Age" in 1. For these reasons the expenditure regressors were excluded from the results reported here but are available upon request.

${ }^{17}$ The fact that the dependent variable lies between 0 and 1 could be problematic in an OLS regression if we had regressors with values in a large range. Here it is not a problem because the right hand side is composed mostly of regressors between 0 and 1 . Nonetheless, we have also estimated the standard transformed equation $\ln \left(\frac{y_{j}}{1-y_{j}}\right)=\beta X_{j}+\varepsilon_{j}$. The conclusions are unchanged (in particular the sign and statistical significance of our measure of male bias), thus we prefer to report the more familiar and easier to interpret case where the dependent variable is not transformed.
} 
although it is not crucial to our argument, that the implicit symmetry assumption - namely that woman vs woman is just like man vs man and that the advantage of a man incumbent (respectively, new man candidate) over a woman is equivalent to the disadvantage of a woman incumbent (respectively, new woman candidate) with respect to a man - is actually supported by the data.

Table 2 reports estimation results. Specifications (1) and (2) only use new candidates while specifications (3) and (4) use incumbents. ${ }^{18}$ Specifications (1) and (3) control for the type of the opponent (either a new candidate, a 1997 loser, or a 1997 winner that was moved to a different district): for (1) the excluded category is an incumbent opponent and for (3) it is a new candidate opponent. These dummies are jointly statistically significant (p-value $<0.1$ ) in specification $(1)$ but not in specification (3) (p-value $>0.1$ ) and thus we also report (2) and (4) where those dummies are excluded. For new candidates, these estimates suggest that it is better to run against any type of candidates than against an incumbent, but that effect is statistically significant only against 1997 losers. Own party score in 1997 and the party position are statistically significant in every specification. Not surprisingly, the effect of own party score in 1997 is positive. ${ }^{19}$ Age difference has a positive impact on score for both new candidates and incumbents, but is statistically significant only for new candidates.

The main finding is a statistically significant male bias, which is observed for both new candidates and incumbents irrespective of the specification. ${ }^{20}$ In appendix 2 we show in Table 4 how this effect differs when a woman faces a woman, a woman

\footnotetext{
${ }^{18}$ In specifications (1) and (2), since we limit attention to new candidates, and since in each second round of each district election the race is $91 \%$ of the time between a new candidate and someone who is not a new candidate, only about $4 \%$ of the new candidates need to be dropped in order to avoid having two candidates from the same district (which would determine correlation between the error terms). However, the results are basically identical with or without such a restriction of the sample. When more than one new candidate ran in the same district, the selection rule was to select male candidates if they ran against a woman, otherwise to select the loser.

${ }^{19}$ One effect of the male bias could be to affect party allegiance as a function of the gender of the candidates, which would suggest interacting own party score in 1997 with gender. In all the regressions reported in the paper, doing so didn't affect overall results and the effect of own party score in 1997 interacted with gender was never statistically significant.

${ }^{20}$ Interacting various indicators of male advantage with the party of the candidates we have also verified that the male advantage is not statistically different across parties.
} 
faces a man, and a man faces a woman, from the baseline where a man faces a man. We show that the hypothesis that woman vs. woman is no different from man vs. man and that the advantage of a man vs a woman equals the disadvantage of a woman against a man cannot be rejected (this is termed the symmetry hypothesis in the table). In the same table, one can notice from columns $3 \mathrm{~b}$ and $4 \mathrm{~b}$ that female incumbents suffered a statistically significant bias, and this could not be explained with a supply shortage argument.

Another way to see if there exists a male bias is to look for the impact of gender on the probability of winning. Table 3 presents logit estimates of the determinants of a win (win equals one and lose equals zero) using the same regressors as for the specifications presented in Table 2. In both specifications (5) and (7) the joint hypothesis that the effect of the type of opponent (new, 1997 loser, or was moved district) is equal to zero cannot be rejected ( $\mathrm{p}$-value $>0.1$ ). For both new candidates and incumbents, all other regressors have the expected sign and are statistically significant. For a male, having an opponent of opposite gender increases the probability of winning - and for a woman it decreases it. The popularity of a candidate's party in 1997 has a significant positive effect. The older the candidate with respect to (her)his opponent, the more likely (s)he is to win, but this effect is decreasing as the age difference increases. Finally, everything else being equal, the UMP candidates were more likely to win in 2002 .

One frequently asked question is whether male bias couldn't be mostly due to experience and/or unobservable quality differences that cannot be captured by the age related observables. At the same age, males are likely to have more experience in politics than female candidates do. To address this, we interact the difference in age and the difference in the square of age with the male advantage variable. ${ }^{21}$ Those estimates for specifications similar to those reported in Table 2 can be found in the Appendix (Table 5). For none of the specifications (1c-4c) are either the age difference interacted with the male advantage or the square of the difference interacted with the male advantage statistically significant, nor are they jointly statistically significant $(\mathrm{p}$-value $>0.1$ ). This is not simply a result of the particular structure of the male advantage variable: if instead we interact the age difference

\footnotetext{
${ }^{21}$ If at a given age men tend to have more (relevant) experience, and this matters to voters, then the interaction variable should be statistically significant.
} 


\begin{tabular}{|c|c|c|c|c|}
\hline \multirow[t]{2}{*}{ Candidates: } & \multicolumn{2}{|c|}{ New } & \multicolumn{2}{|c|}{ Incumbent } \\
\hline & (1) & $(2)$ & $(3)$ & $(4)$ \\
\hline \multirow[t]{2}{*}{ Own Party Score in 1997} & $0.545^{* * *}$ & $0.610^{* * *}$ & $0.504^{* * *}$ & $0.512^{* * *}$ \\
\hline & $(0.054)$ & $(0.049)$ & $(0.043)$ & $(0.043)$ \\
\hline \multirow[t]{2}{*}{ Male Advantage } & $0.014^{* * *}$ & $0.017^{* * *}$ & $0.013^{* * *}$ & $0.014^{* * *}$ \\
\hline & $(0.005)$ & $(0.005)$ & $(0.004)$ & $(0.004)$ \\
\hline \multirow[t]{2}{*}{ Age Difference /100 } & $0.421^{* *}$ & $0.464^{* *}$ & 0.064 & 0.107 \\
\hline & $(0.179)$ & $(0.181)$ & $(0.164)$ & $(0.162)$ \\
\hline \multirow[t]{2}{*}{ Difference of Square of Age /100 } & $-0.005^{* *}$ & $-0.005^{* *}$ & -0.001 & -0.001 \\
\hline & $(0.002)$ & $(0.002)$ & $(0.002)$ & $(0.002)$ \\
\hline \multirow[t]{2}{*}{ Party Right of Center } & $0.081^{* * *}$ & $0.079^{* * *}$ & $0.084^{* * *}$ & $0.083^{* * *}$ \\
\hline & $(0.006)$ & $(0.006)$ & $(0.006)$ & $(0.006)$ \\
\hline \multirow[t]{2}{*}{ Opponent is a New Candidate } & 0.015 & & & \\
\hline & $(0.010)$ & & & \\
\hline \multirow[t]{2}{*}{ Opponent is a 1997 Loser } & $0.034^{* * *}$ & & -0.008 & \\
\hline & $(0.012)$ & & $(0.005)$ & \\
\hline \multirow[t]{2}{*}{ Opponent was Moved } & 0.002 & & -0.027 & \\
\hline & $(0.013)$ & & $(0.029)$ & \\
\hline \multirow[t]{2}{*}{ Constant } & $0.172^{* * *}$ & $0.150^{* * *}$ & $0.235^{* * *}$ & $0.227^{* * *}$ \\
\hline & $(0.025)$ & $(0.024)$ & $(0.024)$ & $(0.024)$ \\
\hline Observations & 248 & 248 & 290 & 290 \\
\hline
\end{tabular}

Standard errors in parentheses

* significant at $10 \%$; ${ }^{* *}$ significant at $5 \%$; *** significant at $1 \%$

Table 2: The Effect of Male Bias on Scores 
Candidate: New Incumbent

\begin{tabular}{|c|c|c|c|c|}
\hline & & \\
\hline & $(5)$ & $(6)$ & $(7)$ & $(8)$ \\
\hline \multirow[t]{2}{*}{ Own Party Score in 1997} & $15.955^{* * *}$ & $18.265^{* * *}$ & $24.373^{* * *}$ & $24.486^{* * *}$ \\
\hline & $(3.641)$ & $(3.448)$ & $(4.112)$ & $(4.069)$ \\
\hline \multirow[t]{2}{*}{ Male Advantage } & $1.007^{* * *}$ & $0.992^{* * *}$ & $0.810^{* *}$ & $0.893^{* * *}$ \\
\hline & $(0.336)$ & $(0.306)$ & $(0.323)$ & $(0.316)$ \\
\hline \multirow[t]{2}{*}{ Age Difference /100 } & $25.635^{*}$ & $24.902^{*}$ & $27.072^{*}$ & $30.707^{* *}$ \\
\hline & $(14.087)$ & $(13.737)$ & $(15.083)$ & $(14.951)$ \\
\hline \multirow[t]{2}{*}{ Difference of Square of Age /100 } & $-0.265^{*}$ & $-0.258^{*}$ & $-0.285^{* *}$ & $-0.317^{* *}$ \\
\hline & $(0.138)$ & $(0.135)$ & $(0.145)$ & $(0.144)$ \\
\hline \multirow[t]{2}{*}{ Party Right of Center } & $3.779^{* * *}$ & $3.493^{* * *}$ & $5.389^{* * *}$ & $5.287^{* * *}$ \\
\hline & $(0.698)$ & $(0.581)$ & $(0.892)$ & $(0.885)$ \\
\hline \multirow[t]{2}{*}{ Opponent is a New Candidate } & -0.145 & & & \\
\hline & $(0.688)$ & & & \\
\hline \multirow[t]{2}{*}{ Opponent is a 1997 Loser } & $1.516^{*}$ & & -0.600 & \\
\hline & $(0.879)$ & & $(0.373)$ & \\
\hline \multirow[t]{2}{*}{ Opponent was Moved } & -0.747 & & -0.245 & \\
\hline & $(0.882)$ & & $(1.486)$ & \\
\hline \multirow[t]{2}{*}{ Constant } & $-10.905^{* * *}$ & $-11.636^{* * *}$ & $-13.074^{* * *}$ & $-13.359^{* * *}$ \\
\hline & $(1.922)$ & $(1.845)$ & $(2.240)$ & $(2.218)$ \\
\hline Observations & 248 & 248 & 290 & 290 \\
\hline
\end{tabular}

Standard errors in parentheses

* significant at $10 \%$; ${ }^{* *}$ significant at $5 \%$; ** significant at $1 \%$

Table 3: The Effect of Male Bias on Winning (Logit) 
and its square with one indicator variable for male candidate with female opponents, and separately interact it with an indicator for female candidate with male opponents, the results are the same: none of the interactions are individually nor jointly statistically significant.

Furthermore, one would expect experience to be less of an issue for incumbents: female incumbents should be expected to have similar office holding experience as men, and we have shown the male advantage to be important for incumbents as well.

A third fact confirming that the male advantage is not simply an artifact of unobserved experience differences is the following: if we estimate specifications 1 and 2 on a subsample of young candidates (more specifically, using the subsample of candidates who are younger than the youngest incumbent in our sample), estimates of the male advantage are still statistically significant (and the coefficient estimate is actually larger at about 0.024 in both specifications), in spite of the fact that in that subsample the office holding experience does not exist for any gender. In other words, the male advantage exists among young new candidates and incumbent candidates, and in both cases there should be a relatively homogeneous experience across genders.

In any case, we stress that even if the source of voters' bias were a perceived experience gap, our main point would be unchanged, since our goal was to show that male advantage is derived from some voters' bias, regardless of where the latter comes from. Moreover, the perception of a male advantage is all we need for the constitutional incentives that we study below in detail in our formal model.

To summarize, men have a statistically higher score when they face a female candidate. A man facing a woman gets about a 1.7 percentage point boost in his score compared to a case where he faces a man. Although this advantage may seem small in magnitude, it has huge implications for the candidates' probability of winning. Using specification (6) we compute the probability of winning for a new male candidate who runs against a female to be 22 percentage points higher than against a male (this is computed setting all other regressors at their sample mean values). ${ }^{22}$ Similar computations using specification (8) reveal that the equivalent

\footnotetext{
${ }^{22}$ To see how the roughly 1.7 difference can be consistent with 22 percent probability difference, note that more than 10 percent of the run-offs have victory of one point or less, and roughly 25
} 
gain for incumbent males is 10 percentage points.

We will now argue that the male advantage just displayed illustrates the existence of some voters' bias rather than a party bias. Indeed, a party bias would take the form of a correlation between gender and the expected score of candidates: men would be sent to districts where the last score is higher. The regressions indicate that even controlling for observables (the 1997 scores, age differences, and party position), there exists a male bias on the voters part. Nonetheless, we will further directly show that women were not victim of a party bias. In Figure 1, we divide the range of 1997 scores into intervals of $2.5 \%$ and present the ratio of new men candidates in districts falling in each interval. It turns out that women are sent to districts where the average 1997 score is equal to $44.72 \%$ while men average is $45.57 \%$. Both a t-test $(\mathrm{p}$-value $=0.30)$ and a Wilcoxon/Mann-Whitney test ( $\mathrm{p}$-value $=0.16)$ cannot reject that the two are equal.

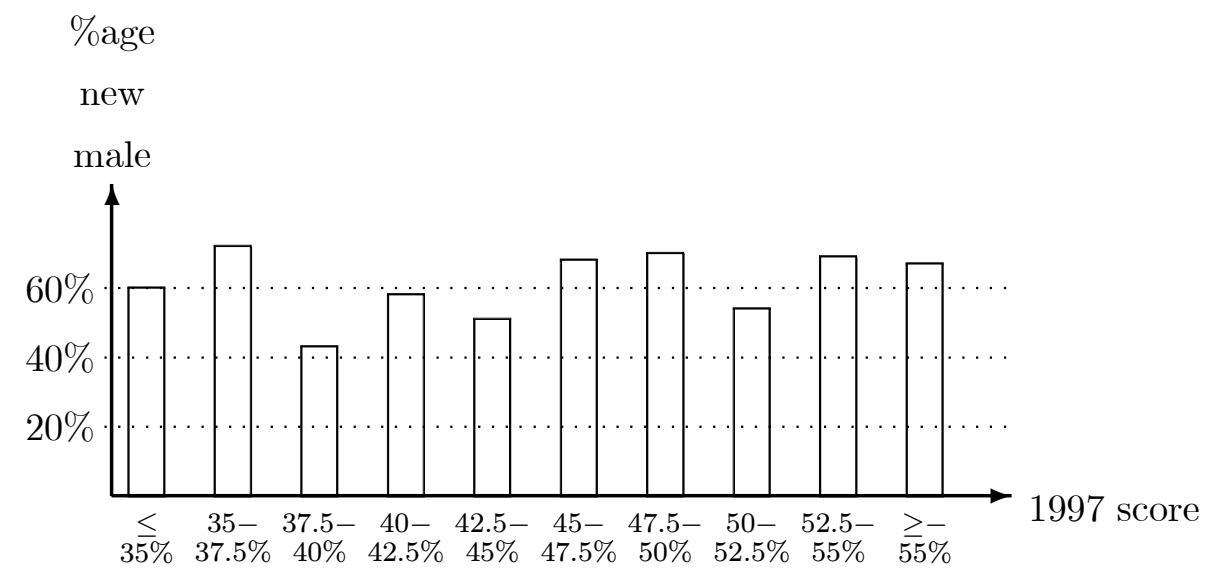

Figure 1: Percentage of new male 2002 candidates as a function of 1997 score of own party

It is useful to distinguish party bias - intended as a pure male conspiracy within parties against women candidates - from a rational party behavior that takes into account the existence of a male bias in the voters' population. We can now discuss percent of run-offs yield more than 48 percent of votes to the loser. 
the evidence about both party bias and party strategic behavior. ${ }^{23}$ Party bias would entail placement of men in districts with high probability of winning (sure winners). Party strategic behavior (without a party bias but with awareness of a voters' bias) would entail, on the other hand, placement of women in both sure losers and sure winners, reserving the men for the tight races. In the sure losers and winners, sending a woman has little impact on the probability of winning, but in the tight races, sending a man greatly improves the odds. Using the estimates from specification (6), we find the 1997 score that implies a 50-50 chance of winning (setting all other regressors to their sample mean values). That number is $51 \%$. For 1997 scores below 51\%, women were sent to districts with 1997 scores of $43 \%$ while men's districts averaged 44\%. For 1997 scores above 51\%, women were assigned districts which averaged 57\% while men's districts averaged $56 \%$. These numbers are in the direction suggested by parties behaving strategically in the face of a male bias in voting, although none of these differences are statistically significant at the $10 \%$ level using either a t-test or Wilcoxon/Mann-Whitney test.

One problem with the accuracy of the controls available to us, is that between 1997 and 2002 many things might have changed, and parties may have information about districts which we do not have, and thus it may be that the bad districts for a given party in 2002 were different from the bad ones in 1997. To address this possibility we again use estimates from specification (6) to construct counterfactual probabilities of winning if parties always presented a candidate of the same gender as the incumbent in every district. This way, we can infer which were the close districts in 2002. We will refer to this counterfactual probability as the "same sex 2002 probability." Table 6 available in the appendix summarizes the results of multiple tests to establish the presence of either party bias or party strategy using both the 1997 and 2002 measures. To test for strategic behavior we define a closeness variable for each year, which is $0.51-\mid 97$ score $-0.51 \mid$ for the 1997 measure and $0.5-$ |same sex 2002 probability $-0.5 \mid$ for 2002. Every test is performed separately for each party as well as jointly. Beside the t-tests, logits are also performed controlling for age, age squared as well as party when the two are combined (the dependent

\footnotetext{
${ }^{23}$ Note that although we argue that the driving force behind the passing of the parity law and its performance is a male bias amongst voters, parties behaving strategically in the face of this bias is not inconsistent with our story.
} 
variable is the gender dummy). One set of logits is done separately with score or closeness, whereas the final set includes both regressors in the same specifications (if score is positive and statistically significant, that would be evidence of party bias, if closeness is, that would be evidence of strategic behavior). An M means that the point (coefficient) estimates suggest a male bias or a party strategy exploiting a male bias in voting, and $\mathrm{F}$ is the same but for females. Overall, there is almost no statistical significance of either (out of the 36 tests reported, only 7 are statistically significant). Strategy is statistically significant more often than party bias. Finally, when both are included, none is ever statistically significant and the party bias is reversed in favor of women in two cases. We conclude that there is little to no evidence of party bias or of strategic behavior, and in relative terms strategic behavior is slightly more likely.

Another way parties could treat woman differently is by giving them less funding for the campaign. There doesn't seem to be any evidence of this. In fact, one party gave on average more to its female candidates. There is, however, a big difference across parties. The UMP gave 10000 Euros to many of its candidate (the median of what it gave is 10000) while the PS gave nothing to a majority of them (its median is 0 ). The UMP gave on average 9539.424 to its female and 9371.369 to its male candidates. The PS gave 1446.088 and 1673.339 to its female and male candidates respectively. For neither party are these numbers statistically different (using either a t-test or a Wilcoxon/Mann-Withney test). Hence, it seems that females were not assigned to districts that were either more difficult to win or easier to win than men. They also did not receive less financial support from their parties.

In conclusion, and in sharp contrast with the common conjectures and previous evidence from other countries, all the evidence and analysis described above indicates that the most likely reason for the male advantage in the 2002 Assembly elections is voters' bias. 


\section{A Model of Constitutional Design Incentives for As- sembly Incumbents}

The Assembly deputies are elected with a two-ballot majority rule. In order to avoid having to deal with strategic voting, in our model we assume that there are only two parties, so that the system is equivalent to one-ballot plurality.

Downs [6] defines a political party as "a coalition of men seeking to control the governing apparatus by legal means," where by coalition he means "a group of individuals who have certain ends in common and cooperate with each other to achieve them." A simple way to operationalize this definition in a theoretical framework is to view a party as a "coalition of incumbents seeking re-election." Given the importance of incumbent politicians in any party hierarchy, it is clear that any party leader will have at least two objectives in mind when choosing the composition of the party candidate list: the maximization of the number of seats the party will obtain and the maximization of the chances of re-election of the party's incumbent politicians. ${ }^{24}$ For simplicity we will also assume that all incumbents are men.

The crucial simplifying assumption of the theoretical model is that if a man candidate runs against a woman he is elected no matter what the voters of that district think of the candidates' policy platforms. This very strong form of male bias is assumed in order to make computations manageable, but the qualitative results do not change if a weaker form of male bias is considered. ${ }^{25}$

Before turning to the more general model, it is important to illustrate the basic intuition. Suppose that we just needed to explain why men incumbents can prefer a "pure" parity law to the status quo without parity. We could give the explanation by means of a simple example: suppose that the country is divided into two districts, so that the Assembly is composed of two incumbents, i.e., the previously elected deputies of those two districts; suppose also that the two incumbents are of the

\footnotetext{
${ }^{24}$ The assumption that parties care about the number of seats obtained by their policy platform as well as about the probability of re-electing incumbents will be kept in order to make the model solvable. After proving our formal proposition using this simplified party objective, we will discuss the implications of extending the model to more complex but perhaps more realistic assumptions about the internal hierarchy of parties.

${ }^{25}$ We will briefly discuss this extension together with the other discussed in the footnote above.
} 
two major parties and that they must run in the district where they were elected (either because it would be illegal or because voters would punish such a switch). If no parity law is passed, the chances of re-election of an incumbent depend on the realization of voters' policy preferences in his district, whereas if a pure parity law is passed, each incumbent is sure to run against a woman (as the men quota will be used by the other incumbent running in his own district), and hence there is an additional advantage, inducing a higher probability of re-election (probability 1 in the case of the extreme gender bias mentioned above). However, explaining why they passed a law that allows parties to pay fees to violate parity is not possible by means of a simple example, and requires a more explicit analysis of all the politicians' incentives.

Let the two parties be denoted by $L$ and $S$. There is a set $[0,1]$ of districts. The current Assembly is composed by the candidates who were elected in the previous elections and are still in office. Districts in $[0, \lambda)$ have an incumbent of party $L$, whereas districts in $[\lambda, 1]$ have an incumbent of party $S$. We assume without loss of generality that $\lambda \geq 0.5$ (party $L$ is the large party).

At time 0 , the deputies vote for a value of $c \in[0, \infty]$, the fee a party needs to pay to circumvent parity in a district. If $c=0$, there is no limit to the number of men running in the country for the same party, that is, there is no parity requirement (the status quo). If $c=\infty$, it is illegal to have more than fifty percent of men running, the pure parity case. If $0<c<\infty$, the law allows parties to send men to any extra measure of districts beyond fifty percent provided the party pays fees equal to $c$ times that extra measure. We need to prove that the vote outcome can be a positive and finite $c$, such that fees are paid in equilibrium under some realization of policy preferences.

At time 1, lists are composed. That is, each party decides whom to run in each district. Incumbents are assumed to re-run in their district if their party decides to run a man in that district. Also, we assume that incumbents cannot shift from their home district to another one. Consequently, if a man runs in a district where the party did not win the previous election, then this man is a new candidate. ${ }^{26}$

\footnotetext{
${ }^{26}$ The implicit assumption is that incumbency is local, and does not constitute an advantage if one switches district. The little evidence of incumbents running in different districts from the one where they had been elected confirms that this assumption is realistic, but the qualitative results of
} 
At time 2, voting takes place. In each district, voters vote for the candidate they prefer. There are only two candidates in each district, hence no strategic voting takes place.

Voters differ in their platform preferences, which can change over time, but they also have very strong gender preferences: Being in favor of the platform of one party translates in a vote for that party unless that party's candidate is a woman running against a man. In the time elapsing between time 0 and time 2, voters' platform preferences may change. At time 2 , districts $[0, z)$ prefer the platform of party $L$, and $[z, 1]$ are in favor of the platform of $S$. The implicit assumption here is that in any possible new realization of voters' platform preferences it cannot happen that district $i$ has a majority of $S$ platform supporters and a district $i^{\prime}>i$ has a majority of $L$ supporters. This order assumption allows us to simplify the treatment of uncertainty at time 0 , since in this way the uncertainty is just about the parameter $z$. The uncertainty about $z$ is greater at time 0 than at time 1 . For simplicity, we assume that it is known at time 1, whereas only the probability distribution is known at time $0 .{ }^{27}$

The utility of an incumbent of party $p, p \in\{L, S\}$, depends on the fraction of seats obtained by his party in the time 2 election, denoted by $N_{p}$; on whether or not he is re-elected; and on the budget of the party, which is affected by the total cost paid by the party to circumvent parity, denoted by $C_{p}$. Formally, for all $i \in[0, \lambda)$

$$
U_{i}=U\left(N_{L}\right)+a I_{i}-\frac{C_{L}}{\lambda}
$$

where $a$ is the utility of being re-elected, $I_{i}$ is the indicator taking value 1 if $i$ is re-elected and 0 otherwise, and $U(N)$ denotes the utility that $i$ derives from the fact that his party obtains a fraction $N$ of the seats. Even though the result could be proved with any $U(N)$ weakly convex for all $N \in[0,0.5)$ and weakly concave for all $N \in(0.5,1]$, the following functional form is the simplest to consider (letting $b$ be a

our model hold even when we allow incumbents to do this kind of shift, but with useless additional computation complexity.

${ }^{27}$ No result depends on the simplifying assumption that $z$ is known at time 1 . Everything would go through in a similar manner if at time 1 there were a less precise update. 
real number in $[0,1))$ :

$$
U(N)=\begin{array}{cc}
b N & \text { if } N<0.5 \\
0.5 & \text { if } N=0.5 \\
1+b N & \text { if } N>0.5 .
\end{array}
$$

For all $i \in[\lambda, 1]$

$$
U_{i}=U\left(N_{S}\right)+a I_{i}-\frac{C_{S}}{1-\lambda}
$$

Consistent with the Downsian view of a party discussed at the beginning of this section, we define a party as the aggregation of its incumbents. Consequently, we assume that the utility of a party is the sum of the utilities of its incumbents:

$$
U_{L}=\lambda U\left(N_{L}\right)+a I_{L}-C_{L}
$$

and

$$
U_{S}=(1-\lambda) U\left(N_{S}\right)+a I_{S}-C_{S}
$$

where $I_{p}$ stands for the number of re-elected incumbents of party $p, p \in\{L, S\}$.

Parity means that there needs to be fifty percent of candidates of each gender for each party. Any deviation from that gender distribution entails a marginal cost of $c$, so that

$$
C_{p}=c\left|M_{p}-0.5\right|, p \in\{L, S\}
$$

where $M_{p}$ is the fraction of men candidates of party $p$ selected at time 1 .

Given all the assumptions above, we have our main theoretical finding:

Proposition 1: If $b$ is small and a is large (i.e., re-electing an incumbent is important for a party but the marginal utility of a new seat is small unless it allows the party to obtain the majority), then there exist well behaved probability distributions of voters' platform preferences such that, at the constitutional choice stage (at time 0), a "parity with fees" system is unanimously preferred to the no parity system, and is preferred by a majority to the pure parity system. 
In a nutshell, we have shown that male bias allows the incumbents to obtain a new type of incumbency advantage by passing an affirmative action law with a progressive cover. The formal proof is in appendix 1. The intuition is similar to the one given for the two-district case as far as the reason for preferring pure parity to the status quo. The intuition for the additional result that parity with fees can dominate even pure parity is as follows: given that a party is a coalition of incumbents and hence re-electing incumbents has priority over electing new candidates, the larger party wants a parity law in order to protect its incumbents in the states of the world in which platform preferences happen to favor party $S$, but given that $L$ 's incumbents are more than fifty percent, pure parity is dominated by a system where even the other $\lambda-0.5$ incumbents can be protected (with some probability) by paying fees. A small $b$ and a relatively large $a$ are needed so that there exist values of $c$ for which parties are ready to pay the fee only if it allows an incumbent to run: indeed, if no such value of c exists, parity with fees cannot be optimal as either the party would refuse to pay to allow one more incumbent to run, or, if the party pays, the opponent party also pays and the incumbent runs against a man, thereby loosing his seat anyway. There are restrictions on the class of admissible distribution functions because the uncertainty to be re-elected needs to be sufficiently large: if a large fraction of incumbents are sure to be re-elected, they may have no incentive to pass the law as it doesn't increase the probability that their party wins the election and it is likely to impose a cut in the budget of the party. However, as one can verify in the appendix, the conditions on $a, b$ and on the skewness of the probability distribution to obtain consensus on parity with fees are very reasonable.

As a corollary of proposition 1, one could easily check from its formal proof that the expected number of women elected given parity law (with fees allowed) is zero. The result is thus very sharp: not only is the parity law as it passed in France perfectly consistent with the self interest of the male incumbents, as proved by proposition 1 , but it is also completely ineffective in terms of the official goals. Of course, using a less extreme type of gender bias than that of this simple model, we could determine a positive (but small) number of expected women elected. In fact, the model could be easily extended relaxing the assumption that a male candidate always wins against a female candidate. We could assume instead that, when voters prefer the political platform of his opponent's party, a male candidate's probability 
of winning is some interior $g>1 / 2$ if the opponent is a woman. Leaving probability 1 of victory in the easier case in which platform preferences are also in his favor, the only change would then be that the expected utility for the party at time 1 of having one additional incumbent running in a district where the voters' preferences have switched decreases. Consequently, the optimal parity with fees system would become one associated with a lower $c$. The equilibrium number of women elected would be strictly positive (but small) in this simple extension.

Another (more interesting) extension could be to assume that parties are "more" than a simple coalition of incumbents. There may well be other potential candidates, besides the incumbents, whose election would increase the party utility by $b+a$, and who come from districts where the other party has an incumbent. Such an extension is particularly relevant for France, as many right wing deputies elected in 1995 lost their seats in 1997 due to the huge (unexpected) victory of the socialist party, and ran again in $2002 .{ }^{28}$ Given the marginal utility for a party to have those candidates running, the equilibrium number of fees paid by the parties increases for most values of $z$, with the possible outcome that both parties pay fees simultaneously, in accordance with what has been observed. This would not affect, however, our main result. Indeed, even if the probability of having to run against a man increases (as the opponent party is more likely to pay the fee and have a male candidate), it is still optimal to have a parity with fees system as it both guarantees that incumbents are still allowed to run, and it increases their probability of running against a woman, in the case where no opponent party member looks for election in that district.

An important corollary of our proposition is that parity may affect the party composition of the Assembly (and hence policies) when voters' platform preferences change with respect to the status quo. The number of seats won by the large party that is losing support in terms of platform preferences is (weakly) larger than if parity was not applied. Thus, the introduction of parity reduces the variance of party composition.

Finally, note that in the informal literature the parties are directly blamed for the low effectiveness of the law (male conspiracy within parties). In our model parties are coalitions of strategic incumbents, so they strategically choose their preferred

\footnotetext{
${ }^{28}$ In 129 districts out of the 361 we analyze there was a candidate who had lost in 1997.
} 
institutional system at time 0 , and they play strategically at the list composition stage. A district where a party is almost sure to win is also one where it has an incumbent, and hence, for the values of the parameter we look at, it is rational for the party to have the incumbent running there. On the other hand, there is no room in the model for male conspiracy, which would bias the party list composition decisions in favor of men just because of their gender. Only self interest matters.

\section{The ex ante and ex post incentives of Senators}

In the previous sections we have first proved empirically the existence of male bias in the electorate, and then we have shown how the ex ante incentives of Deputies and the ex post results were both consistent with a simple rational choice explanation based on male bias itself. In this section we aim to show the corresponding incentives of Senators, although no formal model nor empirical tests are necessary for this chamber.

A senator's term is six years, and a fraction of the Senate is recomposed every three years. The country is divided into a few large districts, and, depending on the population of the district, a number of senators, ranging from 1 to 12, are elected in each district. If the number of seats to be allocated is equal to or below a threshold, then a two-round plurality system is in order and parity does not apply. If the number is above the threshold, then the system is CPR. In this case, parity means that in a party list there cannot be two consecutive candidates of the same gender. The threshold was equal to two in 2001 and to three in 2004.

An essential feature of the senatorial elections is that the set of voters is composed of grands electeurs only, and about $95 \%$ of them are municipality deputies. They had no say in the passing of the parity law, but they tried to influence it through their senators. Municipal elections are two round list elections. A list can run in the second round if it obtains $10 \%$ or more in the first round. The seat allocation rule is proportional with a $50 \%$ seat bonus to the winner. For instance, if a party wins the second round elections with $40 \%$ of the votes and 60 seats are to be allocated, then it will get $30+\left(0.40^{*} 30\right)=42$ seats and the remaining 18 seats are allocated among the other parties proportionally to their second round score. The implementation of the Parity law at the municipal level has this property: out of each set of subsequent 
six candidates in a party list, three have to be women. The only freedom which is left to the parties is the position of the women within each set of six candidates. Given the electoral rule and the amounts of seats allocated in each municipality (varying between 29 and 67), the Parity Law is bound to have a huge effect on the gender composition of the municipal assemblies, and a lot of incumbents must lose their seat. A fraction of them must be thrown out of the list. ${ }^{29}$ Under the pressure of their grands electeurs, Senators obtained the amendment that parity would not apply in municipalities with less than 3500 inhabitants, whereas Assembly deputies first proposed it to apply to all municipalities with more than 2000 inhabitants. Senators also proposed to remove the three women out of six candidate rule, but it was maintained. The percentage of women elected in the municipalities with more than 3500 inhabitants went up from $25.7 \%$ to $47.5 \%$ (thereby making the fraction of women elected in municipal councils rise from $21.7 \%$ to $33 \%$ ).

Protecting their electorate was not the only concern of the senators: They also had to protect their own seats. ${ }^{30}$ Out of the 74 (resp., 72 ) incumbent senators looking for re-election in 2001 (resp., 2004) in districts where CPR applies, only 5 (resp., 8) were women. Before the law was passed, senators tried to obtain the amendment that no alternating gender rule apply for the senatorial elections, but failed. ${ }^{31}$ Nevertheless, only 20 seats - $28 \%$ - (resp., 26 - 32.9\% -) went to female candidates. Given the number of districts where parity does not apply and the low effectiveness where it applies, the percentage of women is $16.6 \%$.

What did senators resort to, in order to circumvent the law? The answer is what

\footnotetext{
${ }^{29}$ The intuitive reason for the effectiveness of parity with a two-round PR system with majority bonus is that with this system most municipalities ended up with one party holding a large majority of the seats, and if -say - the elected members of such a party are 30, the law described in the text makes sure that 15 of them are women.

${ }^{30}$ The simple computations contained in this section use the electoral outcomes presented on the website of the French senate, http://www.senat.fr/. The details of the computation are available upon request.

${ }^{31}$ Senators have a weaker role in France relative to many other countries. "The Senate's legislative powers are limited; the National Assembly has the last word in the event of a disagreement between the two houses." (US Department of State (2004)) This is clearly visible in Title V Article 45 of the Constitution "If the joint committee does not succeed in adopting a common text, or if the text is not adopted as provided in the preceding paragraph, the Government may, after a further reading by the National Assembly and by the Senate, ask the National Assembly to make a final decision."
} 
we call party proliferation. ${ }^{32}$ Out of the 29 districts where proportional elections were held in 2001 or 2004, party proliferation (incumbents previously elected under the same flag now running under different ones) took place in 11 of them. In 8 other cases candidates elected on different lists registered as members of the same senatorial group after the election. ${ }^{33}$ Finally, in several other districts, candidates previously active in the same party, though new in the senatorial race, ran on different lists, with two examples of such lists obtaining more than 10 percent. Party proliferation has clearly been a wide phenomenon in both elections, which explains the low effectiveness of parity. ${ }^{34}$

Let us now analyze more closely the phenomenon of strategic party proliferation in CPR. We first describe the conditions under which party proliferation is most likely to happen. Then we study its effect on the party composition of the Assembly.

\subsection{Party proliferation}

The cost of creating a party is relatively low for the senators. Given the grands electeurs system and the size of the districts, the actual number of votes needed to obtain a seat varies between 260 and 892. Moreover, those are councillors themselves and senators have regular opportunities to meet them. Let us consider a party likely to obtain a score of $s$ and an associated number of $k$ seats, with $k$ male incumbents. Let $k$ be an even number. It seems reasonable to assume that the incumbent's advantage is decreasing among candidates from the leader of the list to the $k$ th elected: popularity decreases with rank. Given parity, only $\frac{k}{2}$ incumbents can be given positions among the first $k$ positions, those leading to a seat with

\footnotetext{
${ }^{32}$ This is illustrated by the Meurthe-et-Moselle district, where 4 seats had to be allocated. Two right-wing incumbents had been elected under the same party flag before. They split the list, created two new parties, ran on the top of their respective list (followed, as required by the law, by a woman) and got re-elected.

${ }^{33}$ Although, by definition, those examples involve new candidates to the senatorial elections, these candidates do typically have incumbent-type advantages, as they are former ministers, deputies, region presidents, etc.

${ }^{34}$ Proliferation of party lists has probably been made easier by the fact that senators have a unique type of (small) electorate, the grands electeurs. However, Jones [9] (table 2) shows, among other things, that some kind of list proliferation also took place in Costa Rica after the introduction of gender quotas (excluding the main two parties).
} 
some likelihood. Therefore, the $\left(\frac{k}{2}+1\right)$ th incumbent is pivotal in the proliferation process. His only chance of being elected is in creating his own list and diverting at least $\frac{s}{k+1}$ voters from the main party. This score is necessary, as the score of the main party, down to $\frac{k s}{k+1}$, is otherwise still superior to $k$ times that of the dissident list. This may not be sufficient, however, since other parties may have a larger d'Hondt score for the last seat and obtain the formerly $k$ th seat of that party. To illustrate this fact, let us consider a district where three parties compete for 8 seats and the distribution of scores is $(45,27.5,27.5)$, so that the allocation of seats is $(4,2,2)$. After the parity reform, incumbent 3 of the first party is ejected from the first positions on the list. By running on his own and obtaining 10 percent of the votes, which corresponds to scores $(35,10,27.5,27.5)$, he would keep his seat. If we compare that result with the situation where there is only one opponent party and the scores are $(45,55)$ before parity and $(35,10,55)$ after proliferation by incumbent 3 , we now have a distribution of seats going from $(4,4)$ to $(3,0,5)$. The lower bound in the second situation is now 11 and the scores $(33.9,11.1,55)$ then lead to $(3,1,4)$. Let us also note that any two incumbents ejected from the main party list have no incentive to create a joint list, as, given parity, their joint list would have to win three seats for them both to be elected.

Let us assume that the $\left(\frac{k}{2}+1\right)$ th incumbent is sure to keep his seat if he creates his own list. Then the probability that the $\frac{k}{2}$ th incumbent be elected on the main list decreases, as the new score of the main party may no longer be sufficient to obtain $k-2$ seats. Moreover, if the $\left(\frac{k}{2}+1\right)$ th incumbent is able to be elected by running on his own, then so is the $\frac{k}{2}$ th incumbent, given the assumption that individual popularity decreases with the rank. The prudent strategy by candidate $\frac{k}{2}$ is therefore to create his own list too, which, in turn, decreases the probability of the $\left(\frac{k}{2}-1\right)$ th incumbent to be elected.

From this simple argument we can infer that proliferation is the more likely the more popular is the $\left(\frac{k}{2}+1\right)$ th incumbent, but the unravelling may determine a situation in which the incumbents who actually are observed making the split are higher in the rank. If $k$ is large, it may be impossible to have a sufficiently large popularity for the $(k / 2+1)$-th incumbent and, at the same time, a decreasing order of popularity. This leads to the following: 
Remark: Party proliferation is more likely when (1) the incumbency advantage is more equal among candidates and (2) the number of incumbents on the list, and/or the number of seats expected by a list, is lower.

The example and the reasoning above all assume that the scores are perfectly expected. Proliferation is also more likely when the uncertainty of being elected by running on one's own is lower. When the number of seats to be allocated in a district and the number of relevant parties are larger, then the competition for the last seats to allocate is larger, which increases the uncertainty.

This explains why, given that districts have on average a relatively small number of seats, parity had low effect in the senatorial elections.

\subsection{Assembly composition effect}

Parity may also affect the Assembly composition under CPR. There are two different effects. One is the large party effect, playing in a similar way as under SMD: if a party has more incumbents than half the total number of seats, then it has to lose the votes associated with the incumbency advantage of the incumbents it ejects from the list. Clearly, this may affect the score of the party, and, therefore, the number of seats it gets.

The second effect is directly associated to party proliferation. In the example above, proliferation by incumbent 3 led to a change in the Assembly composition from $(4,4)$ to $(3,0,5)$ which means a shift of one seat from left to right. The example may look extreme, as the proliferation was a failure. However, other examples may be given of successful proliferation affecting the Assembly composition. Consider a district where two parties compete for 6 seats. The expected scores are $(43,57)$, which would lead to a $(3,3)$ allocation of seats. Assume that, indeed, there are three incumbents out of each platform. Again, we may think that incumbent 3 of the left party can profitably create his own list, thereby preventing incumbent 2 from keeping his own seat. The equilibrium list composition is therefore one where the left party has split into two lists, led by incumbents 1 and 2 respectively. Let us assume that the resulting distribution of votes is $(24,19,57)$, the resulting seat allocation is $(1,1,4)$ : proliferation by left incumbent 2 is successful, but increases the number of seats obtained by the right party. 
The composition effect arising from the conflicting interests of an incumbent seeking to keep his seat and a party seeking to maximize the number of seats obtained by candidates sharing its platform is likely to affect both large and small parties. It is well known that under the d'Hondt system a party can never gain by splitting, as the d'Hondt coefficients cannot rise as a result of a split. As a consequence, the platform which loses is always the one where proliferation takes place. As it is clear from the example, proliferation is more likely to result in a loss of seats when the d'Hondt coefficient of the party as a whole is the lowest among all parties.

The above characterization of party proliferation has some implications for the advocates of gender quota legislations. Given that the probability of success after the creation of a new list is obviously lower when there is a minimum threshold necessary to obtain seats, one can conjecture that a system with PR, large districts and a minimum threshold is the most desirable for the representation purposes, although in a closed list system the details of the law in terms of placement rules are crucial. Another way to create barriers to party proliferation is by enlarging the districts and, correspondingly, the number of seats to allocate in the districts. First, this reduces the expected incumbent's advantage of the pivotal incumbent. Second, as the number of competing parties is larger in larger districts, the competition for the last seats to allocate is larger, thereby increasing the sensitivity of the total number of seats obtained by a platform to the way the total number of votes is divided between the lists obtained by proliferation from one party.

\section{Concluding Remarks}

The common criterion used to evaluate representation reforms, such as the parity law in France, is the effectiveness of the reform: did it help increase the percentage of women elected? In the literature on descriptive representation the objective to increase the number of women in politics finds many justifications. ${ }^{35}$ Among the countries where voluntary or mandatory gender quotas have been attempted, it is clear that the highest effectiveness has been achieved in countries using PR with large districts (see e.g. Jones [9], table 1). However, such international comparisons

\footnotetext{
${ }^{35}$ On the problem of under representation of women in Parliaments and Cabinets see Siaroff [15] and Rosenthal [13].
} 
do not elaborate on the causality, and it would not be wise to use them directly for normative purposes. There could be cultural factors that co-determine the type of electoral reform and the type of gender quota rules, and the perception of gender preferences could in fact affect the politicians' preferences over electoral rules, reversing the causal links.

The French parity law reform of 2001, as pointed out in the introduction, stands out from all other gender representation reform experiences for many reasons, including the fact that it allowed us to distinguish the incentives of politicians elected through different electoral systems within the same context, hence without cultural differences. The incumbents were interested in not losing their positions, and deputies knew they were the least challenged by the reform. Had they passed a pure parity system without allowing for per violation fees, and had there been a demand among voters for new female candidates, then of course the law would have been effective. On the other hand, the analysis of this paper suggests that the parity law was passed precisely because voters were expected to respond the way they did, and combining this with the permission to pay fees for some strong established male candidates, the law could not be effective.

There exist of course combinations of electoral rules and gender quota rules that guarantee effectiveness, regardless of whether there is a "demand" for more women in office or not (see e.g. the municipal elections example given in the previous section). However, here is where the trade-offs between desirability and feasibility of multiple institutional reforms become evident: suppose we all agree that women's representation should increase (even if the current French voters do not display such a demand). Given the evidence and the analysis of this paper, it is quite clear that the advocates of a more equal representation should be in favor of a more proportional electoral system; on the other hand, had the electoral system for the National Assembly been more proportional, probably the Deputies would have displayed a similar opposition to that displayed by Senators, and the parity law reform would not have been approved in its form. Consistent with this observation, note that all the gender quota legislations passed in countries using CPR have a minimum quota for women in party lists between 20 and 40 percent, with an average below 30 percent (see once again Jones [9], table 1). Proposing a 30 percent quota allows the party leaders in a closed list system to make the law pass without losing 
their seats, since the votes of the 70 percent of the Parliament expecting to be re-elected (plus the vote of incumbent women) suffice to pass the law in spite of the supermajority often required for constitutional reforms. The only two types of systems in which passing a fifty percent quota is consistent with rational calculus by party leaderships are (1) any system where the expected effectiveness is very low in any case, like in the French case studied here, or (2) an open list electoral system, in which the strong and well established incumbents had no worries because the order in the lists would not matter (see the case of Belgium).

Another important remark is that obviously a reform of an electoral system is influenced by multiple considerations, and descriptive representation is only one of them. Introducing quotas into a mixed system like the French municipal system is very effective but advocating for a shift towards that system for national elections involves forgetting about its important drawback of allowing even small parties to obtain the majority of the seats (in the extreme case, a party with a little bit more than $10 \%$ of the votes in the first round can end up obtaining $100 \%$ of the seats). ${ }^{36}$

A final set of remarks can be made on the comparison between France and other countries that use single member district elections for their members of Parliament. A natural question is why has parity law come up in France and not in other countries with similar electoral systems for their deputies. Our conjecture is that this may have to do with the perceived gender preferences of the electorate. In the US states there seems to be no evidence of voters' hostility against women, nor much evidence in favor of the male conspiracy theory. Thus, there is no "demand side" clear explanation for the low number of women in politics (see e.g. Darcy et al. [5] and Welch et al. [16]). Implicitly this implies a mostly "supply side" story for the U.S. The sharp contrast between our study on the French case and the earlier studies on the U.S. ${ }^{37}$ suggests an intriguing hypothesis to be tested in future research: Countries where voters' gender bias exists have fewer women than men because of a "demand" bias, and are more likely to endogenously generate affirmative action laws;

\footnotetext{
${ }^{36}$ The sense in which this is a drawback refers to standard ex-ante welfare criteria. See for example Morelli [12] for a suggestive welfare comparison of electoral systems.

${ }^{37}$ Note that our empirical analysis is based on field data, whereas the studies just mentioned on the U.S. are based on survey data, and we have no way to say to what extent these sharp differences could be due to this.
} 
on the other hand, countries like the U.S. where no voters' demand bias exists, and where therefore the shortage of women in politics is a "supply" issue, are unlikely to have the necessary conditions for the approval of a parity law.

As part of our future research on endogenous affirmative action or, more generally, on endogenous institutional reform due to incumbents' interests, we plan to extend the theoretical as well as the empirical analysis to campaign financing: there is a great variation of campaign financing and party funding laws across democracies, and we conjecture that campaign financing restrictions, as much as the gender quotas studied in this paper, may well be motivated by the same objectives of incumbent politicians. Moreover, the politicians of countries with different electoral systems are likely to value different kinds of "institutional complementarities" with campaign financing laws, and it is our goal to continue to uncover these different types of institutional complementarities. 


\section{References}

[1] Burrell, B.C. (1998): "The Political Opportunity of Women Candidates for the US House of Representatives in 1984," Women and Politics Vol. 8, 51-68.

[2] Caul, M. (2001): "Political Parties and the Adoption of Candidate Gender Quotas: a Cross-National Analysis," Journal of Politics, Vol. 63(4), 1214-1229.

[3] Commission Nationale des Comptes de Campagne et des Financements Politiques (2003), "Publication Simplifiée des Comptes de Campagne, " Journal Officiel de la République Francaise Edition des Documents Administratifs, Journaux Officiels.

[4] Darcy R. and S. Schramm (1977), "When Women Run Against Men," Public Opinion Quarterly, Vol. 41(1), 1-12.

[5] Darcy R., S. Welch, and J. Clark (1994), Women, Elections, and Representation, University of Nebraska Press, 2nd edition.

[6] Downs, A. (1957), An Economic Theory of Democracy, New York, Harper.

[7] Duflo, E. and R. Chattopadhyay (2004), "Women as Policy Makers: Evidence from a Randomized Policy Experiment in India," Econometrica, 72(5), 1409-43.

[8] Duverger, Maurice (1955), The Political Role of Women, Paris: Unesco.

[9] Jones, M.P. (2004): "Quota Legislation and the Election of Women: Learning from the Costa Rican Experience," Journal of Politics, Vol. 66(4), 1203-23.

[10] Jourdain, S. (2002), "Parité bien votée commence par les autres," Libération, July 13 .

[11] Matland, R.E. And D.T. Studlar (1996): "The Contagion of Women Candidates in Single-Member District and Proportional Representation Electoral Systems: Canada and Norway," Journal of Politics, Vol. 58(3), 707-733.

[12] Morelli, M. (2004), "Party Formation and Policy Outcomes under Different Electoral Systems," Review of Economic Studies, 71(3), 829-53. 
[13] Rosenthal, C.S. (1995): "The Role of Gender in Descriptive Representation," Political Research Quarterly, Vol. 48, 599-611

[14] Sanbonmatsu, K. (2002) "Political Parties and the Recruitment of Women to State Legislatures," Journal of Politics, Vol. 64(3), 791-809.

[15] Siaroff, A. (2000): "Women's Representation in the Legislatures and Cabinets in Industrial Democracies," International Political Science Review, Vol. 21(2), 197-215.

[16] Welch, S., M.M. Ambrosius, J. Clark and R. Darcy (1985), "The Effect of Candidate Gender on Election Outcomes in State Legislative Races," Western Political Quarterly, Vol. 38(3), 464-475.

[17] Zimmerman, M.-J. "Pourquoi la parité en politique reste-t-elle un enjeu pour la démocratie française?" Paris: Services du Premier Ministre - Observatoire de la parité entre les femmes et les hommes, March 2003. 


\section{Appendix 1: Proof of proposition 1}

Once $z$ is known, the country is conceptually divided into three regions: $[0, \min \{z, \lambda\})$; $[\min \{z, \lambda\}, \max \{z, \lambda\}] ;$ and $[\max \{z, \lambda\}, 1]$. Parties $L$ and $S$ play a list composition game, and a strategy is an assignment of a man or a woman in each district. Formally, a strategy is an element of $\{0,1\}^{[0,1]}$ where 0 (resp. 1) means that a woman (respectively, a man) is sent to that district. Denote by $m_{p}^{j} \in[0,1]$ the fraction of men candidates running for party $p, p \in\{L, S\}$, in region $j, j \in$ $\{[0, \min \{z, \lambda\}),[\min \{z, \lambda\}, \max \{z, \lambda\}),[\max \{z, \lambda\}, 1]\}$.

Given our assumptions on voters' platform preferences and gender preferences, each party wants to send men where the other party sends men if the platform preference of the voters is favorable, or send men where the opponent sends women if the opposite is true. This leads to the following lemma:

Lemma 1 In any Nash equilibrium of the list composition game played at time 1 by the two parties, each party uses the same mixed strategy in every district of the same region, and hence an equilibrium strategy of party $p$ can be summarized by the triplet $\left(m_{p}^{j}\right)$.

Proof. Suppose instead that party $S$ puts a man running in district $i$ with probability $m_{S}(i)<m_{S}\left(i^{\prime}\right)$, where $i$ and $i^{\prime}$ are in the same region $j$.

Then if $j$ is a region in which $L$ wins the man-man races the best response is to have $m_{L}\left(i^{\prime}\right)>m_{L}(i)$; but this could not be compatible in equilibrium with the hypothesis, since the best response to the latter inequality for party $S$ must have the feature $m_{S}(i)>m_{S}\left(i^{\prime}\right)$.

A similar contradiction arises if $j$ is a region in which $S$ wins the man-to-man races: In this case the best response by $L$ would have to satisfy $m_{L}(i)>m_{L}\left(i^{\prime}\right)$, but this in turn cannot be compatible in equilibrium with the hypothesis, since the best response to the latter inequality by party $S$ would be $m_{S}(i)>m_{S}\left(i^{\prime}\right)$. QED.

The list composition game is, therefore, equivalent to a game where parties have to decide on proportions of men in each of the three regions. Suppose for example that $z<\lambda$ (the voters' support of the $L$ platform has decreased since the last election). Then parties have to decide on $m_{p}^{0 z}, m_{p}^{z \lambda}, m_{p}^{\lambda 1}$. The result is that a fraction $m_{L}^{0 z}+\left(1-m_{L}^{0 z}\right)\left(1-m_{S}^{0 z}\right)$ of $L$ candidates are elected in region $[0, z)$, as all 
the men are elected, and, among the women who run (in proportion $\left(1-m_{L}^{0 z}\right)$ ), all those who end up running against a woman also win the election, and the probability of running against a woman is $\left(1-m_{S}^{0 z}\right)$.

Having explained the strategies for any probability distribution over $z$, let us now choose a specific probability distribution that will allow us to prove the result. Assume that $z$ can take values in $\{0,1-\lambda, \lambda, 1\}$, with corresponding probabilities equal to $0.5-f, f, f, 0.5-f$, for some $f \in(0.25,0.5)$. (Thus $f$ measures the skewness of the distribution.)

Assume that $b$ is infinitesimally small, so that it justifies a seat maximizing behavior ceteris paribus but it can be ignored in the computations. Given this assumption, the utility of party $L$ is

$$
U_{L}=\int_{i \leq \lambda} U_{i} d i=\begin{array}{cc}
\lambda+a I_{L}-C_{L} & \text { if } N_{L}>0.5 \\
0.5 \lambda+a I_{L}-C_{L} & \text { if } N_{L}=0.5 \\
a I_{L}-C_{L} & \text { if } N_{L}<0.5
\end{array}
$$

and

$$
\begin{aligned}
& U_{S}=\int_{i \geq \lambda} U_{i} d i=(1-\lambda)+a I_{S}-C_{S} \quad \text { if } N_{S}>0.5 \\
& 0.5(1-\lambda)+a I_{S}-C_{S} \quad \text { if } N_{S}=0.5 \\
& a I_{S}-C_{S} \quad \text { if } N_{S}<0.5 .
\end{aligned}
$$

Consider first the status quo $(c=0)$. At time 1 , it is a dominant strategy for both parties to have only male candidates. the expected utility is then:

$$
\begin{array}{lll}
\forall i \quad \in[0,1-\lambda): & U_{i}^{e}=a f+(1+a) f+(0.5-f)(1+a) \\
& =(0.5+f) a+0.5 ; \\
\forall i \quad \in[1-\lambda, \lambda): & U_{i}^{e}=(1+a) f+(0.5-f)(1+a) \\
& =0.5(1+a) ; \\
\forall i \quad \in[\lambda, 1]: & U_{i}^{e}=(0.5+f) a+0.5 .
\end{array}
$$

Consider next the pure parity case $(c=\infty)$. We first analyse the equilibrium of the list composition subgames in the four possible cases, and then we deduce the expected utility of each incumbent. 
Case 1: $z=0$; the 0.5 men candidates sent by $S$ will be elected, and necessarily at least some women will be elected too, so that $S$ will win the election. It is optimal for $S$ to have all its incumbents running. Therefore, in region $[0, \lambda]$, , by lemma 1 , the equilibrium strategies are $m_{L}^{0 \lambda}=\frac{0.5}{\lambda}$ and $m_{S}^{0 \lambda}=\frac{\lambda-0.5}{\lambda}$ in every district of that region. Consequently, each $L$ incumbent has a probability $\frac{0.5}{\lambda}$ of running, and, if he runs, a probability $\frac{0.5}{\lambda}$ of being elected. All $S$ incumbents are sure to be re-elected.

Case 2: $z=1-\lambda$. Sending all its 0.5 men to districts in $[1-\lambda, 1]$ guarantees 0.5 seats, and $S$ is sure to have more than that, so, again, $S$ is sure to win the election. The equilibrium strategies are $m_{L}^{0 z}=1, m_{L}^{z \lambda}=\frac{1}{2}, m_{L}^{\lambda 1}=0$ and $m_{S}^{0 z}=0, m_{S}^{z \lambda}=\frac{1}{2}, m_{S}^{\lambda 1}=1$. Incumbents in $[0, z)$ and $[\lambda, 1]$ are sure to be re-elected, whereas incumbents in $[z, \lambda)$ run with probability $\frac{1}{2}$ and, if they run, are elected with probability $\frac{1}{2}$.

Cases 3 and 4: $z=\lambda$ or $z=1$. $L$ wins the election. In this case party $L$ tries to send men where $S$ sends men, and $S$ tries to send men where $L$ sends women. Equilibrium strategies are $m_{L}^{0 \lambda}=\frac{0.5}{\lambda}, m_{L}^{\lambda 1}=0$ and $m_{S}^{0 \lambda}=\frac{\lambda-0.5}{\lambda}, m_{S}^{\lambda 1}=1$. Incumbents from region $[0, \lambda)$ run with probability $\frac{0.5}{\lambda}$ and are sure to be re-elected if they run.

The expected utilities computed at time 0 are as follows.

$$
\begin{aligned}
\forall i \in[0,1-\lambda): & U_{i}^{e}=(0.5-f) \frac{0.5^{2}}{\lambda^{2}} a+a f+0.5\left(1+\frac{0.5}{\lambda} a\right) \\
& =\left(\frac{0.5^{2}}{\lambda^{2}}(\lambda+0.5-f)+f\right) a+0.5 ; \\
\forall i \quad \in[1-\lambda, \lambda): \quad & U_{i}^{e}=(0.5-f) \frac{0.5^{2}}{\lambda^{2}} a+0.5^{2} a f+0.5\left(1+\frac{0.5}{\lambda} a\right) \\
& =\frac{0.5^{2}}{\lambda^{2}}\left(\lambda+0.5-\left(1-\lambda^{2}\right) f\right) a+0.5 ; \\
\forall i \quad \in[\lambda, 1]: \quad & U_{i}^{e}=0.5(1+a)+0.5 a \\
& =a+0.5 .
\end{aligned}
$$

It is easy to see that $S$ incumbents strictly prefer pure parity to no parity, as it guarantees their re-election.

Let us now consider the case of parity with fees $\left(c=c^{*} \in(0, \infty)\right)$. Take in particular any value of $c^{*}$ such that

Assumption a: $a / 2>c^{*}>b \approx 0$. 
Case 1: $z=0$. At equilibrium, $S$ must win the election. Indeed, it has at least 0.5 seats (all its men are elected), and, if it is not sufficient to win, then it is worth paying the fee for one male candidate. So we can consider that $S$ wins the election with 0.5 men running. $S$ tries to maximize the number of seats obtained, so that the equilibrium will be mixed, with $M_{S}$ (the number of men running for $S$ in $[0, \lambda))$ equal to $\lambda-0.5$. The utility of party $L$ is $U_{L}=a \frac{0.5}{\lambda} M_{L}-c^{*}\left(M_{L}-0.5\right)$ where $M_{L}$ stands for the number of men running in $[0, \lambda)$. Rearranging, we get $U_{L}=\left(\frac{0.5}{\lambda} a-c^{*}\right) M_{L}+0.5 c^{*}$, so that $L$ pays the fees for all its incumbents whenever $\frac{0.5}{\lambda} a-c^{*}>0$, that is, $a>2 c^{*} \lambda$, which holds given assumption a. Therefore, all the incumbents run, and 0.5 of them are elected. The average utility among them is $\frac{0.5}{\lambda} a-\frac{c^{*}(\lambda-0.5)}{\lambda}$, whereas the utility of each $S$ incumbent is $1+a$.

Case 2: $z=1-\lambda$. As above, $S$ is sure to win, provided it runs all incumbents from $\lambda$ to 1 and the remaining men $(\lambda-0.5)$ randomly in the interval $[z, \lambda]$. It has no incentive to take a man from $[\lambda, 1]$ to $[z, \lambda)$, given that $c^{*}>b$, nor to $[0, z)$, as the probability for a man to be elected in that region is 0 . If a man from party $L$ runs in $[z, \lambda]$, then his probability of being elected is 0.5 . Utility of party $L$ is $U_{L}=(1-\lambda) a+0.5\left(M_{L}-(\lambda-0.5)\right) a-c^{*}\left(M_{L}-0.5\right)$. So party $L$ will pay the fees, given assumption a. For each incumbent in $[0,1-\lambda), U_{i}=a-\frac{c^{*}}{\lambda}(\lambda-0.5)$, and the average utility of those from $[1-\lambda, \lambda)$ is $0.5 a-\frac{c^{*}}{\lambda}(\lambda-0.5)$. The utility of incumbents of $S$ is $1+a$.

Case 3: $z=\lambda$. For a similar reason as above, $L$ is sure to win. Party $S$ sends all its incumbents, and sends men uniformly in $[0, \lambda)$. We have $U_{L}=1+a M_{L}-$ $c^{*}\left(M_{L}-0.5\right)$, so that $M_{L}=\lambda$, all to be re-elected. The utility of each $L$ incumbent is $1+a-\frac{c^{*}}{\lambda}(\lambda-0.5)$, and that of $S$ incumbents is $a$.

Case 4: $z=1$. The fact that $L$ men are sure to be elected even if they run in $[\lambda, 1]$ does not change the strategy from the previous case, as paying the fee for having one more male candidate elected is not profitable if he is not an incumbent. The equilibrium utilities are, therefore, identical to what they are in case 3.

The expected utility of the incumbents can be computed as follows (letting $C^{*}$ 
stand for $\left.\frac{c^{*}}{\lambda}(\lambda-0.5)\right)$ :

$$
\begin{array}{ll}
\forall i \quad \in[0,1-\lambda): & U_{i}^{e}=(0.5-f)\left(\frac{0.5}{\lambda} a-C^{*}\right)+f\left(a-C^{*}\right)+0.5\left(1+a-C^{*}\right) \\
& =\left((0.5-f) \frac{0.5}{\lambda}+f+0.5\right) a+0.5-C^{*} ; \\
\forall i \quad \in[1-\lambda, \lambda): \quad & U_{i}^{e}=(0.5-f)\left(\frac{0.5}{\lambda} a-C^{*}\right)+f\left(0.5 a-C^{*}\right)+0.5\left(1+a-C^{*}\right) \\
& =\left((0.5-f) \frac{0.5}{\lambda}+0.5 f+0.5\right) a+0.5-C^{*} ; \\
\forall i \quad \in[\lambda, 1]: \quad & U_{i}^{e}=0.5(1+a)+0.5 a \\
& =a+0.5 .
\end{array}
$$

\section{At time 0:}

Let us now compare the expected utility of each incumbent across the different possible values of $c$.

1) For incumbents in $[0,1-\lambda)$ : it is clear that parity with fees is the system which maximizes their probability of being re-elected. But the other consequence is that fees have to be paid. We have that parity with fees is better than no parity iff $a \geq 2 c^{*} \frac{\lambda-0.5}{0.5-f}$, which can only be satisfied if $0.5-f$ is not too small. Let us note that a very low $0.5-f$ means that those incumbents are almost sure to be re-elected even without parity, so that it is intuitive that no parity is the best system for them. Given our assumptions, it is sufficient to have $0.5-f>\lambda-0.5$, which is reasonable, in order to have the incumbents in this region strictly prefer parity with fees to no parity. Strict parity is better than no parity iff $0.5-f>2 \lambda(\lambda-0.5)$, which again means that the probability to be in a bad state is sufficiently large; but observe that the threshold is more difficult to satisfy than in the previous case (it is more likely to have parity with fees better than no parity than strict parity better than no parity). Parity with fees is better than pure parity iff $a \geq \frac{2 \lambda c^{*}(\lambda-0.5)}{\lambda(\lambda-f)-0.5(0.5-f)}$, which is satisfied if the condition above for parity with fees to dominate no parity holds. Thus, parity with fees is the best for those incumbents if $0.5-f$ is sufficiently large.

2) For incumbents in $[1-\lambda, \lambda):$ parity with fees is preferred to no parity iff $a>$ $2 c^{*} \frac{\lambda-0.5}{0.5-(1-\lambda) f}$. But we have already assumed that $a>2 c^{*}$, and the fraction is always lower than 1. Parity with fees is preferred to strict parity iff $a>2 c^{*} \frac{\lambda(\lambda-0.5)}{(1-\lambda) f+\lambda^{2}+0.5^{2}}$, and again the fraction is always smaller than 1 . Consequently, parity with fees is 
always the strictly most preferred solution in this region.

3 ) The incumbents in $[\lambda, 1]$ all strictly prefer a parity law, with whatever $c>0$, to the status quo.

Consequently, given assumption a, there are many probability distributions with many possible skewness levels such that parity with fees is strictly preferred by the majority (the $L$ incumbents) to any other system. Given the strict preference by the $S$ incumbents for any type of parity law over the status quo, the parity with fees reform could win against the status quo even if the voting rule was unanimity. QED. 
Appendix 2 


\begin{tabular}{|c|c|c|c|c|}
\hline \multirow[t]{2}{*}{ Candidate: } & \multicolumn{2}{|c|}{ New } & \multicolumn{2}{|c|}{ Incumbent } \\
\hline & $(1 b)$ & $(2 \mathrm{~b})$ & $(3 \mathrm{~b})$ & $(4 \mathrm{~b})$ \\
\hline \multirow[t]{2}{*}{ Own Party Score in 1997} & $0.541^{* * *}$ & $0.612^{* * *}$ & $0.497^{* * *}$ & $0.504^{* * *}$ \\
\hline & $(0.053)$ & $(0.049)$ & $(0.044)$ & $(0.044)$ \\
\hline \multirow[t]{2}{*}{ Male candidate with Female Opponent } & $0.027^{* * *}$ & $0.029 * * *$ & $0.011^{* *}$ & $0.012^{* *}$ \\
\hline & $(0.010)$ & $(0.009)$ & $(0.006)$ & $(0.006)$ \\
\hline \multirow[t]{2}{*}{ Female candidate with Male Opponent } & -0.007 & -0.010 & $-0.017^{* *}$ & $-0.018^{* *}$ \\
\hline & $(0.007)$ & $(0.007)$ & $(0.008)$ & $(0.008)$ \\
\hline \multirow[t]{2}{*}{ Female candidate with Female Opponent } & -0.011 & -0.007 & 0.012 & 0.014 \\
\hline & $(0.011)$ & $(0.011)$ & $(0.012)$ & $(0.012)$ \\
\hline \multirow[t]{2}{*}{ Age Difference /100 } & $0.445^{* *}$ & $0.486^{* * *}$ & 0.075 & 0.114 \\
\hline & $(0.179)$ & $(0.181)$ & $(0.164)$ & $(0.163)$ \\
\hline \multirow[t]{2}{*}{ Difference of Square of Age /100 } & $-0.005^{* * *}$ & $-0.005^{* * *}$ & -0.001 & -0.001 \\
\hline & $(0.002)$ & $(0.002)$ & $(0.002)$ & $(0.002)$ \\
\hline \multirow[t]{2}{*}{ Party Right of Center } & $0.080^{* * *}$ & $0.079^{* * *}$ & $0.083^{* * *}$ & $0.083^{* * *}$ \\
\hline & $(0.006)$ & $(0.006)$ & $(0.006)$ & $(0.006)$ \\
\hline \multirow[t]{2}{*}{ Opponent is a New Candidate } & 0.013 & & & \\
\hline & $(0.011)$ & & & \\
\hline \multirow[t]{2}{*}{ Opponent is a 1997 Loser } & $0.037^{* * *}$ & & -0.007 & \\
\hline & $(0.012)$ & & $(0.005)$ & \\
\hline \multirow[t]{2}{*}{ Opponent was Moved } & 0.001 & & -0.026 & \\
\hline & $(0.013)$ & & $(0.029)$ & \\
\hline \multirow[t]{2}{*}{ Constant } & $0.172^{* * *}$ & $0.146^{* * *}$ & $0.239 * * *$ & $0.232^{* * *}$ \\
\hline & $(0.025)$ & $(0.024)$ & $(0.025)$ & $(0.024)$ \\
\hline Observations & 248 & 248 & 290 & 290 \\
\hline F-Test of Symmetry Hypothesis (p-values) & 0.121 & 0.193 & 0.454 & 0.392 \\
\hline
\end{tabular}

Standard errors in parentheses

* significant at $10 \% ; * *$ significant at $5 \%$; *** significant at $1 \%$

Table 4: The Effect of Male Bias on Scores 


\begin{tabular}{|c|c|c|c|c|}
\hline \multirow{2}{*}{ Candidate: } & \multicolumn{2}{|c|}{ New } & \multicolumn{2}{|c|}{ Incumbent } \\
\hline & $(1 \mathrm{c})$ & $(2 \mathrm{c})$ & $(3 \mathrm{c})$ & $(4 c)$ \\
\hline \multirow[t]{2}{*}{ Own Party Score in 1997} & $0.543^{* * *}$ & $0.609^{* * *}$ & $0.504^{* * *}$ & $0.513^{* * *}$ \\
\hline & $(0.054)$ & $(0.049)$ & $(0.043)$ & $(0.043)$ \\
\hline \multirow[t]{2}{*}{ Male Advantage } & $0.015^{* * *}$ & $0.018^{* * *}$ & $0.012^{* *}$ & $0.012^{* * *}$ \\
\hline & $(0.006)$ & $(0.005)$ & $(0.005)$ & $(0.005)$ \\
\hline \multirow[t]{2}{*}{ Age Difference /100 } & $0.433^{* *}$ & $0.481^{* *}$ & 0.129 & 0.162 \\
\hline & $(0.198)$ & $(0.200)$ & $(0.188)$ & $(0.187)$ \\
\hline \multirow[t]{2}{*}{ Difference of Square of Age /100 } & $-0.005^{* *}$ & $-0.005^{* *}$ & -0.002 & -0.002 \\
\hline & $(0.002)$ & $(0.002)$ & $(0.002)$ & $(0.002)$ \\
\hline \multirow[t]{2}{*}{ Age Difference x Male Advantage /100 } & 0.049 & 0.074 & -0.166 & -0.137 \\
\hline & $(0.295)$ & $(0.297)$ & $(0.270)$ & $(0.270)$ \\
\hline \multirow[t]{2}{*}{ Difference of Square of Age x Male Advantage /100 } & 0.000 & -0.001 & 0.002 & 0.002 \\
\hline & $(0.003)$ & $(0.003)$ & $(0.003)$ & $(0.003)$ \\
\hline \multirow[t]{2}{*}{ Party Right of Center } & $0.081^{* * *}$ & $0.079^{* * *}$ & $0.083^{* * *}$ & $0.082^{* * *}$ \\
\hline & $(0.007)$ & $(0.006)$ & $(0.006)$ & $(0.006)$ \\
\hline \multirow[t]{2}{*}{ Opponent is a New Candidate } & 0.014 & & & \\
\hline & $(0.010)$ & & & \\
\hline \multirow[t]{2}{*}{ Opponent is a 1997 Loser } & $0.034^{* * *}$ & & -0.008 & \\
\hline & $(0.012)$ & & $(0.005)$ & \\
\hline \multirow[t]{2}{*}{ Opponent was Moved From Another District } & 0.001 & & -0.029 & \\
\hline & $(0.013)$ & & $(0.029)$ & \\
\hline \multirow[t]{2}{*}{ Constant } & $0.173^{* * *}$ & $0.150^{* * *}$ & $0.235^{* * *}$ & $0.227^{* * *}$ \\
\hline & $(0.025)$ & $(0.024)$ & $(0.024)$ & $(0.024)$ \\
\hline Observations & 248 & 248 & 290 & 290 \\
\hline
\end{tabular}

Standard errors in parentheses

* significant at $10 \%$; ${ }^{*}$ significant at $5 \%$; ** significant at $1 \%$

Table 5: The Effect of Male Bias on Scores 


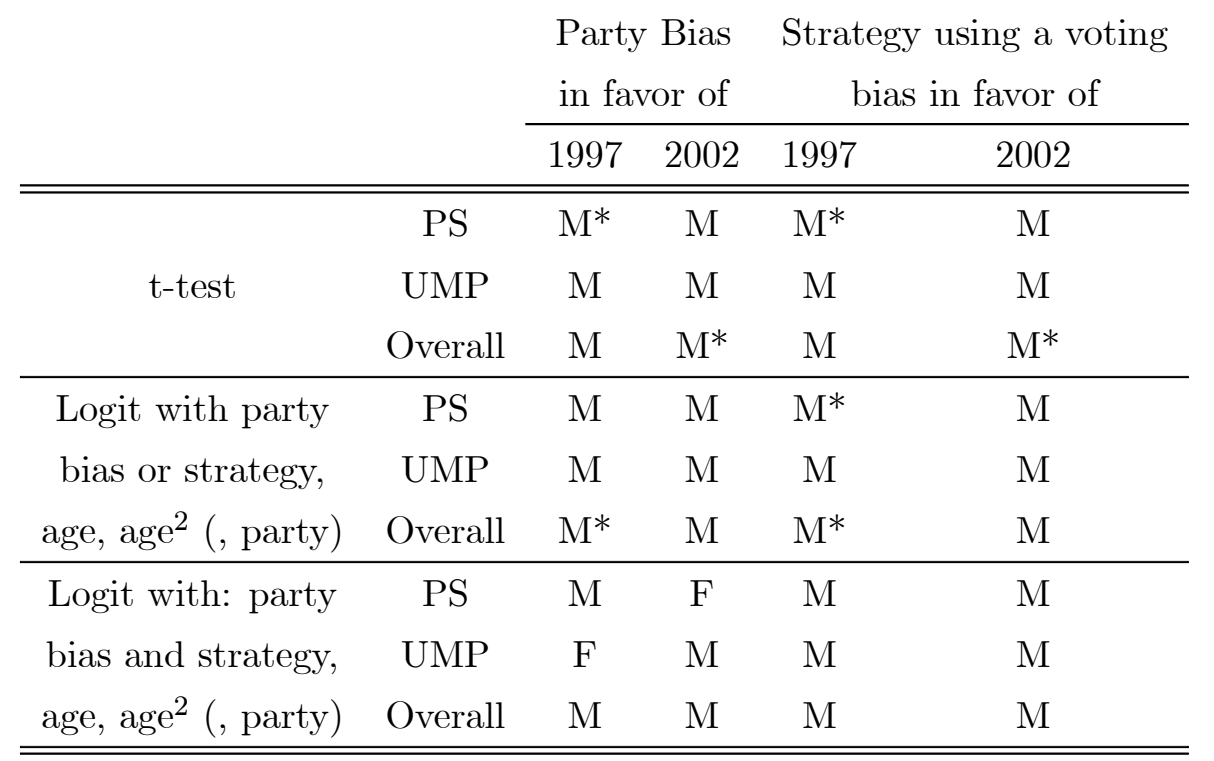

* significant at $10 \% ;{ }^{* *}$ significant at $5 \%$; ${ }^{* * *}$ significant at $1 \%$

$\mathrm{M}$ stands for male and $\mathrm{F}$ for female.

Table 6: Party Bias or Strategy? 
Département des Sciences Économiques de l'Université catholique de Louvain

Institut de Recherches Économiques et Sociales

Place Montesquieu, 3

1348 Louvain-la-Neuve, Belgique 